\title{
Os Estados Unidos entre o nacional e o transnacional: o saber produzido pela circum-navegação científica da U.S. Exploring Expedidion (1838-1842)
}

Mary Anne Junqueira*

Resumo: Trata-se de analisar alguns aspectos do conhecimento moderno expresso no relato de viagem da primeira circum-navegação científica, U. S. Exploring Expediton, entre 1838-1842. Os conjuntos de saberes constituídos pela expedição estiveram entre a afirmação nacional e os aspectos transnacionais próprios da época. Revela-se o propósito norte-americano no que diz respeito à inserção de quadros do país na rede de conhecimento liderada pelos europeus, discutindo com os seus pares do velho continente, mas também concorrendo com eles.

Palavras-chaves: Estados Unidos. Circum-Navegação. Ciência. Nacional. Transnacional.

\section{Introduçáo}

Em 1838, levantava âncoras da costa leste dos Estados Unidos uma ambiciosa e cara operação. Devidamente aprovada pelo Congresso, a U. S. Exploring Expedition era a primeira viagem científica de circum-navegação além-mar dos Estados Unidos. Com seis navios (Vincennes, Peacock, Porpoise, Relief, Sea Gull, Flying Fish), reparados para receber os expedicionários - 346 homens, entre oficiais, cientistas e marinheiros - o trabalho da expedição demandou quatro anos, de 1838 a 1842 . Pouco conhecida entre

* Professora-Associada do Departamento de História e do Instituto de Relaçōes Internacionais (USP). Financiamento: FAPESP. Contato: maryjunq@usp.br. 
os historiadores e outros especialistas, a espetacular expedição foi marginalizada no âmbito da memória nacional do país que costuma apregoar os grandes feitos do seu passado (PHILBRICK, 2005). O material produzido pela expedição é volumoso. $\mathrm{O}$ relato de viagem de 23 volumes é composto por cinco dedicados à narrativa de viagem propriamente dita e outros 18 volumes científicos, cuidadosamente preparados após aportarem de volta em águas nacionais em 1842.

$\mathrm{O}$ foco de interesse da U. S. Exploring Expedition — como de outras circum-navegaçóes dos séculos XVIII-XIX - concentrou-se nas ilhas do Oceano Pacífico, onde os navios deslocaram-se para trabalhos semelhantes em locais diferentes. Entretanto, havia outras regióes de interesse dos norte-americanos, por exemplo: a costa oeste da América do Norte (Califórnia, entáo província mexicana, e Oregon, território em disputa). Além dessas duas regióes de interesse, os expedicionários trataram amplamente da América do Sul e da Ásia, já de volta para a casa.

Comandava a expedição o capitão-tenente, Charles Wilkes, que liderava outros 37 oficiais (o número variou durante a viagem exploratória), sete cientistas, dois artistas, além dos marinheiros. Como se sabe, viagens como a mencionada, realizadas pelas Marinhas de Guerra, eram operaçóes estratégicas e carregavam muitos objetivos, alguns declarados, outros náo. $\mathrm{O}$ trabalho de primeira ordem da exploraçáo era o mapeamento náutico, como em outras viagens do mesmo tipo, o dos cientistas estava em segundo plano no âmbito dos interesses do governo. (JUNQUEIRA, 2008)

$\mathrm{O}$ presente artigo pretende mostrar que os anos nos quais os Estados Unidos realizaram a U. S. Exploring Expedition são elucidativos do momento de transformaçóes referentes ao âmbito da "institucionalização do conhecimento" naquele país. A jovem República procurava formar quadros e estabelecer os campos do saber em órgáos governamentais, universidades e outras instituiçóes científicas, em geral, espelhando-se no que estava em desenvolvimento na Europa. Mas, ora em diálogo, ora em concorrência com os europeus, eles buscavam participar das redes de conhecimento ocidentais, particularmente as alimentadas por cientistas e militares. Ainda que advogassem um saber local com base em disciplinas e correntes científicas, o conhecimento sobre o globo já era transnacional 
(SALVATORE, 2007). Veremos que a viagem exploratória foi central para a concretização de determinados projetos nessa área.

\section{A tarefa primordial: o mapeamento náutico}

O mapeamento, como mencionado, era tarefa primeira da viagem exploratória. Tal prioridade é revelada no destaque particular conferido à divisão do trabalho entre oficiais e cientistas nas instruçôes do secretário da Marinha, James Kirke Paulding, ao Capitão Charles Wilkes:

Embora o objetivo primeiro da Expedição seja a promoção dos grandes interesses do comércio e navegação, você considerará as oportunidades, as quais náo sejam incompatíveis com os notáveis objetivos já propostos para estender os limites da Ciência e promover a aquisição de conhecimento. Para que obtenha sucesso nessa empresa, um corpo científico de gentlemen consistindo nos nomes que se seguem, acompanhará a Expedição e estará sob sua direção. Sr. Hale (filólogo), Srs. Pickering e Peale (naturalistas), Sr. Couthouy (conquiliologista), Sr. Dana (mineralogista), Sr. Rich (botânico), Srs. Drayton e Agate (artistas), Sr. Brackenridge (especialista em horticultura). Quanto à Hidrografia e à Geografia dos vários mares e países, você deve visitá-los na rota já indicada nas instruçôes precedentes; você e também todos os pesquisadores relacionados devem prestar especial atenção à Astronomia, ao magnetismo terrestre e à Meteorologia. Essas tarefas são confiadas exclusivamente aos oficiais da Marinha, aos quais o zelo e os talentos, o Departamento confidencialmente acredita para que tais resultados habilitem futuros navegadores a navegar no rastro percorrido por seus veleiros, sem temor e sem perigo (PAUDING, 1838, p. XXX apud WILKES, Narrative, v. 1, 1845, p. XXX).

As tarefas estavam claramente divididas: a ênfase de Paulding recaiu sobre as consideradas estratégicas, às quais Wilkes deveria "[...] dedicar a sua especial atenção" (PAULDING, 1844, p. XXX). Ele 
salientou a importância da Hidrografia (estudo das águas da Terra, verificação de desembocadura dos rios, identificação das características dos oceanos, levantamento das plantas de costas e ilhas, identificação de baixios ou outros acidentes submersos que oferecessem riscos às embarcaçóes etc.) e, consequentemente, da Astronomia e do magnetismo terrestre. O domínio desses campos era considerado indispensável para a elaboração de cálculos para confecção acurada de cartas e a localização precisa dos navios, fosse próximo às costas, fosse em alto mar. Tarefas essas que deveriam permanecer nas mãos dos oficiais da U. S. Navy. Note-se que com objetivos claros de formar novos quadros para a instituição. Em segundo lugar, e "[...] aproveitando a ocasiáo [...]” (PAULDING, 1844, p. XXX), nos dizeres do Secretário da Marinha, estavam os cientistas também subordinados ao capitão que indicava onde e por quanto tempo deveriam trabalhar.

\section{O U. S. Coast Survey e a formaçáo de quadros da U. S. Navy}

Charles Wilkes, antes de aceitar o posto de comandante da expedição, fora chefe do Depot of Charts and Instruments de Washington, o órgão responsável por centralizar a tecnologia de navegação nos Estados Unidos e predecessor do The United States Naval Observatory, fundado em 1842. Ali, os oficiais primavam por manter a acuidade dos instrumentos náuticos, em particular dos cronômetros. Conferir a exatidão desses mecanismos era imprescindível, já que erros mínimos nas mediçôes significavam desacertos de muitas milhas náuticas (DICK, 1992). É importante ressaltar que, na época, os cientistas, militares e governos, munidos dos seus cronômetros e outros instrumentos, procuravam a precisa localização em alto mar e discutiam a instituição dos meridianos da Terra. (JUNQUEIRA, 2012)

Wilkes apurou-se nas artes da cartografia, em 1833, quando era responsável pelo mapeamento de Narragansett Bay, estuário entrecortado no litoral de Rhode Island. Ele vinha se qualificando no campo, desde a década de 1820, ao trabalhar com o reconhecido suíço, Ferdinand Hassler, matemático, cartógrafo e interessado em Geodésia. Hassler chegara aos Estados Unidos pelas mãos do então 
presidente Thomas Jefferson (1801-1809), após aceitar o convite para instalar no país o U. S. Coast Survey, o órgáo responsável pelo mapeamento acurado da costa leste norte-americana, uma vez que o trânsito de navios comerciais ali demandava segurança (WILKES, 1978; WILFORD, 2000).

Wilkes também estudou com Nathaniel Bowditch, conhecido matemático norte-americano, que, entusiasmado com a acurácia dos mapas do oficial, indicou-o para o comando da viagem exploratória (WILKES, 1978, p. 326-327). O método de mapeamento com base na triangulação já era usado anteriormente na Europa e era prática nas viagens similares de mapeamento, desde o século XVIII (BAEZA; LEIVA, 2004, p. 132). Com Hassler, no entanto, o método ganhou rigor e sofisticaçáo nos Estados Unidos. $\mathrm{O}$ aprendizado com especialistas internos e externos à academia naval garantiu a Wilkes os conhecimentos necessários para a aplicação do método de triangulação na fabricação de cartas em outras águas, que não as nacionais, já amplamente utilizado por Ferdinand Hassler.

\section{Conferindo cartas antigas, construindo novas}

Embora a expedição concentrasse esforços no Pacífico e na costa noroeste da América do Norte, o próprio Oceano Atlântico ainda carecia de mapeamento acurado e a expedição não se furtou a isso. Aqui, registro apenas alguns pontos mapeados pela U. S. Exploring Expedition no oceano mencionado para demonstrar o trabalho realizado náo apenas no Atlântico, mas também em outras águas. Novamente, as instruçôes do Secretário de Estado James Kirke Paulding:

Tão logo os veleiros estejam prontos em todos os aspectos, você [Charles Wilkes] consequentemente partirá de Norfolk e tomará o curso para o Rio de Janeiro, atravessando a linha entre longitudes $18^{\circ}$ e $22^{\circ} \mathrm{W}$., e se mantendo entre esses meridianos em torno da latitude $10^{\circ} \mathrm{S}$., no intuito de determinar a existência e as posiçōes corretas de baixios e acidentes submersos, os quais se acredita existir, e que estáo colocados como "em dúvida" nas cartas. É útil verificá-los em 
razão dos interesses do nosso comércio. (PAUDING, 1844 apud WILKES, Narrative, v. 1, 1845, p. XXV).

Esse excerto confirma a existência de cartas imprecisas e a urgência com que os Estados Unidos procuravam dirimir esses problemas. Veremos que, em primeiro lugar, eles se esforçavam para firmar um saber próprio, nacional, participando de um trabalho conjunto, na busca por inserção nas redes transnacionais de conhecimento científico que vinham se estabelecendo desde o século XVIII. Refiro-me àquelas compostas por homens que se colocavam como autores e membros das academias científicas e reivindicavam as suas prerrogativas intelectuais através da publicação de textos nos quais as suas acepçóes eram centrais (ZAFIER, 2008, p. 25). Simultaneamente, eles procuravam se posicionar internacionalmente como o país que dominava aspectos da ciência e da técnica da época.

No Atlântico, próximos à Ilha da Madeira, os cartógrafos da U. S. Exploring Expedition, antes de baixarem âncoras no porto do Rio de Janeiro - a partir da longitude precisamente tomada e tendo Greenwich como referência — eles localizaram um baixio, conhecido como Maria Rock, que já havia surpreendido outros expedicionários. Wilkes informa nas primeiras páginas da narrativa,

O primeiro baixio alcançado, Maria Rock, é considerado em latitude $19^{\circ} .45^{\prime}$ N., e longitude 20 $50^{\prime}$ W. Em sua vizinhança, a nossa posição foi cuidadosamente acertada. Os veleiros se espalharam em ordem aberta e em curso navegaram para passar diretamente sobre o lugar. A superfície do oceano visível era não menos que 20 milhas em latitude [36,56 km], com a oportunidade que o tempo claro poderia oferecer. Bons observadores foram mantidos no topo do mastro e havia movimentação suficiente para causar colisóes com qualquer baixio a 15 pés [ $4,57 \mathrm{~m}$ ] da superfície. Movemo-nos sobre o local sem perceber qualquer coisa que indicasse o acidente submerso (WILKES, Narrative, v. 1, 1845, p. 30).

$\mathrm{O}$ acidente geográfico submerso foi assim chamado em razão do navio português, Maria, ter soçobrado ali em 1821. Nessa passagem, 
o comandante demonstra perícia ao localizar e mapear acuradamente um acidente submerso e incerto nos mapas náuticos existentes da regiáo do Atlântico. Aos poucos, os expedicionários iam conferindo cartas, preenchendo "lacunas" das já existentes ou mesmo construindo outras novas (WILSON, 2003, p. 181-219).

Os viajantes dialogavam com outros que os haviam precedido na realização do mesmo trabalho de mapeamento e deixavam registradas informaçóes e indicaçóes para os próximos que se aventurariam em mesmas águas. Assim, esse trabalho de mapeamento da Terra configurava-se a partir de esforço conjunto e transnacional.

Essa troca de informaçôes e constatações principalmente entre os militares-cartógrafos mostra o trabalho transnacional realizado em relação ao mapeamento do globo, entre a segunda metade do século XVIII e a primeira do XIX. No entanto, as viagens científicas, como vimos, eram operações estratégicas e com finalidades geopolíticas.

Ainda que o secretário da Marinha e Charles Wilkes reconhecessem a dívida para com outros navegadores, o trabalho da U. S. Exploring Expedition — como o de outras circum-navegaçóes - era visto como exclusivamente nacional. Já em águas argentinas, e próximo à Patagônia, Wilkes informou sobre mapeamento do navio Relief:

Existe um baixio a oeste do Cabo de Três Pontas, ao qual o comandante Long [do Relief] depois de ancorar, enviou três botes para examiná-lo. A menor profundidade encontrada foi de sete braças (mais ou menos $12.8 \mathrm{~m}$.), presumiu-se ser a continuação do baixio de Byron. $\mathrm{O}$ rochedo Bellaco foi visto na latitude 48 $30^{\prime}$ S., longitude 66 $07^{\prime} 11^{\prime}$ ' W. Existe outro rochedo que se curva a $S .17^{\circ}$, por volta de nove ou dez milhas [18,2 km] de distância, em latitude 48 38' $44^{\prime}$ S., longitude $66^{\circ} 03^{\prime} 53^{\prime}$ W. Esse último rochedo foi encontrado em posição correspondente com o de Bellaco de Nodales. Parece, portanto, que existem dois rochedos, e que aquele indicado pelo capitão Stokes não é o verdadeiro Bellaco. Contudo, ele está na posição indicada por Nodales em 1619; é provável que o Relif seja o primeiro veleiro que tenha indicado a presença de ambas. Essa discrepância se deve, possivelmente, ao fato de o verdadeiro Bellaco ter estado 
coberto pela maré quando o capitão Stokes passou por essa parte da costa. (WILKES, Narrative, v. 1, 1845, p. 115-116).

Esse excerto é exemplar para verificarmos como o trabalho de mapeamento era realizado em conjunto com outras naçóes e tendo outras - e anteriores —, narrativas de viagem como objeto de discussão. Eles debatiam as imprecisóes encontradas em outras cartas e em outros relatórios de viagem e procuravam estabelecer a localização correta. Novamente, o trabalho não era feito sem rivalidades e concorrências. Nota-se, aqui e ali, o entusiasmo de Wilkes em "acertar" a localização estabelecida por um predecessor.

Wilkes menciona também John Byron, navegador inglês que completou a circum-navegação em 1764, e Pringle Stokes, da mesma nacionalidade, homem que comandou o Beagle na primeira viagem à América do Sul, em 1826. Nessa data, o Beagle fazia a sua primeira viagem (1826-1830), acompanhando um veleiro maior, o Adventure, comandado por Philip Parker King em viagem de mapeamento. A história da primeira viagem do Beagle é trágica, visto que Stokes, acometido por grave depressão, suicidou-se na Terra do Fogo. A segunda viagem do Beagle (essa sim de circum-navegação do globo), na qual esteve embarcado o naturalista Charles Darwin, se deu entre 1831-1836 (DESMOND; MOORE, 2000).

As indicaçóes são de que, ao mencionar Nodales, Wilkes referia-se aos irmáos Bartolomé e Gonzalo García Del Nodal, navegantes que mapearam o extremo austral da América do Sul, no século XVII. Eles indicaram uma nova rota ao sul da Terra do Fogo como alternativa para a passagem do Atlântico ao Pacífico pelo Estreito de Magalhães. Para fazer o levantamento geográfico, o capitão da U. S. Exploring Expedition dialogava com os cartógrafos dos séculos XVII, XVIII e XIX que haviam reconhecido a região anteriormente, e indicava o êxito da sua viagem ao afirmar que o Relief, um dos veleiros da expedição, havia dirimido a incerteza.

A seguir, apresento um exemplo do trabalho de mapeamento, com base na triangulação, trigonometria e outros cálculos que configuravam o método de triangulação, utilizado para a cartografia de ilhas e retirado do primeiro volume da narrativa. 
Figura 1 - Exemplo do mapeamento por triangulaçáo.

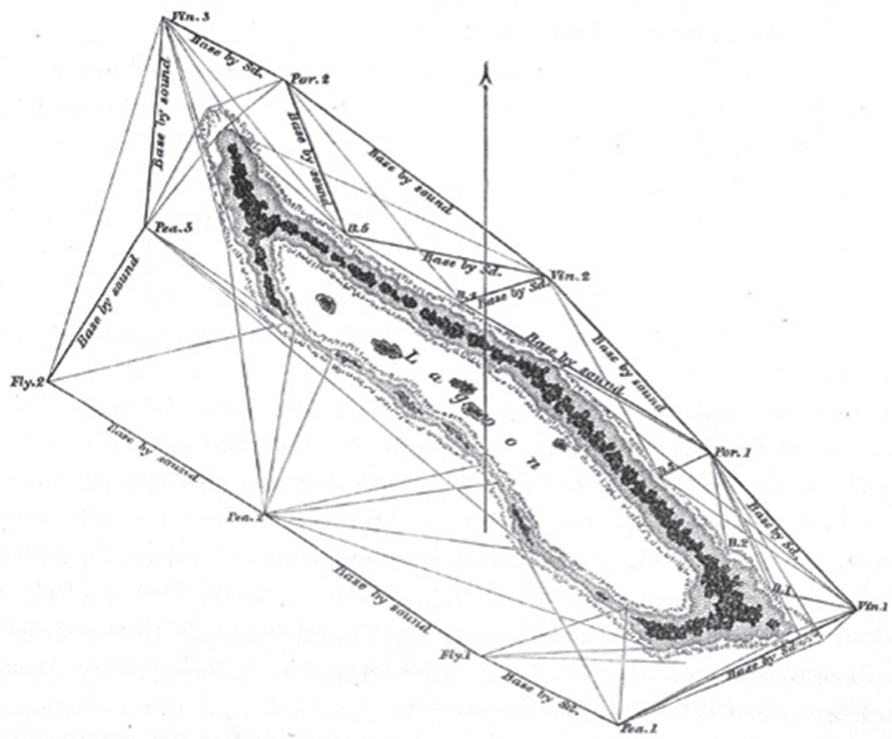

Fonte - (WILKES, Narrative, 1845, v. 1, p. 452)

\section{Um outro continente: a disputa pela Antártida}

Se o comércio fora o principal argumento para que a expedição obtivesse a aprovação no Congresso e o devido financiamento, principalmente no que tangia à caça à baleia, o esforço em nome da ciência veio em seguida. Desde 1828, a promoção de uma expedição científica financiada integralmente pelo governo ganhava corpo e circulava em jornais e meios acadêmicos e militares.

Jeremiah Reynolds, jovem editor e influente jornalista, foi um dos lobistas que insistiram, junto ao Congresso, para que fosse realizada a viagem científica. Reynolds era partidário da ideia de John Cleves Symmes - ex-oficial do Exército, interessado em Física e Geologia - que propunha que fossem verificados os polos da Terra. Segundo o cientista amador, havia indicaçóes da existência de enormes buracos 
nos polos do globo, em razão da semelhança dos animais que habitavam as duas extremidades. Symmes publicou vários textos sobre o assunto, o que fez a sua teoria relativamente popular na época. Ele deduzia que a Terra era uma esfera sólida, achatada nos extremos, mas oca no centro, o que indicava a possibilidade de vida no seu interior. Symmes muito divulgou a sua teoria e chegou mesmo a arrecadar fundos para uma possível viagem comprobatória ao Polo Norte.

Jeremiah Reynolds encampou o projeto de Symmes (hollow earth theory) e, em nome da ciência, reivindicou que uma expedição de circum-navegação dedicasse especial atenção aos polos e conferisse a suposição de Symmes (VIOLA, 1985; STANTON, 1975; PHILBRICK, 2003). Hoje em dia, tal teoria parece-nos desmedida e demasiado fantasiosa. Apesar de infundada, a ideia de Symmes - por causa da divulgação que teve e da repercussão que alcançou — foi considerada tanto por cientistas como por interessados em geral. ${ }^{1}$ Mais relevante do que as hipóteses pouco plausíveis da época é o que o fato em si revela: o planeta era ainda desconhecido na primeira metade do século XIX, incidindo em demandas pelo domínio de saberes - o que certamente cobriria de glória os autores de determinadas especulaçóes e o país que financiasse a comprovação.

Todavia, o que a teoria de Symmes - que ajudou a impulsionar a aprovação da U. S. Exploring Expedition —, e a própria realização da expedição demonstram é que os Estados Unidos investiam na construção de um saber local, fortalecendo universidades e outras instituições científicas. Em outras palavras, buscavam "institucionalizar o saber", superando assim o amadorismo da jovem nação. 


\section{Figura 2 - Modelo usado por John Cleves Symmes (hollow earth theory) nas suas apresentaçóes sobre o tema.}

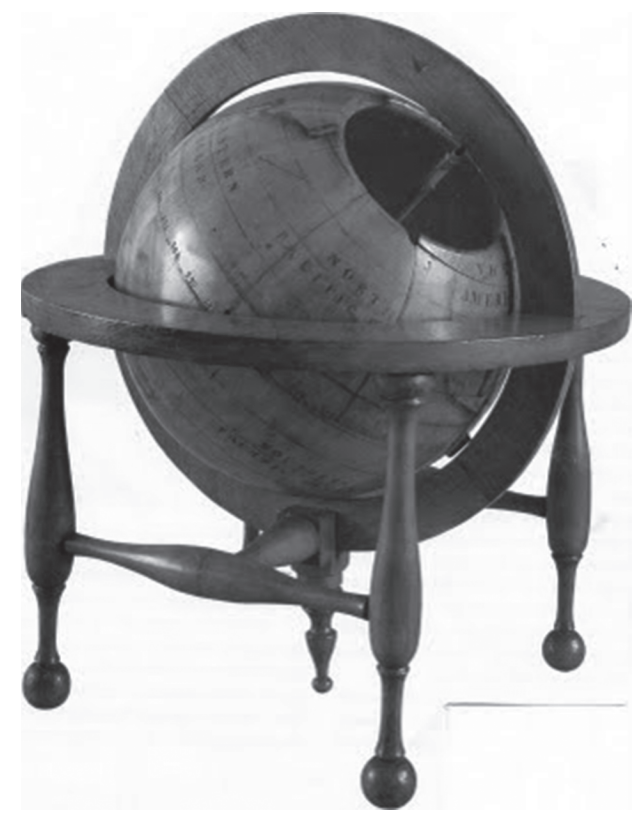

Fonte: The Academy of Natural Science of Drexel University. Disponível em: http:// ansp.org/explore/online-exhibits/stories/habitable-within/. Acesso em: fev. 2015.

Enquanto o Vincennes permanecia em Orange Harbour, outros navios deslocavam-se rumo ao continente gelado. Finalmente a U. S. Exploring Expedition chegara à Antártida. No entanto, o que ali se verificou estava longe da especulação de Symmes. Na época, foi considerada a mais notável realização da expedição, o fato de Charles Wilkes demonstrar que a Antártida era outro continente, além dos já conhecidos (Europa, Ásia, África, América, Oceania). Embora, tenha havido controvérsia se cabia aos norte-americanos, franceses ou ingleses a primazia da descoberta, hoje em dia, os autores creditam aos oficiais da U. S. Exploring Expedition a façanha de terem sido os 
primeiros a avistar terra no local, fato que comprovava a existência de outro continente no planeta. ${ }^{2}$

\section{Legenda - Mapa1}

$\frac{6}{6}$

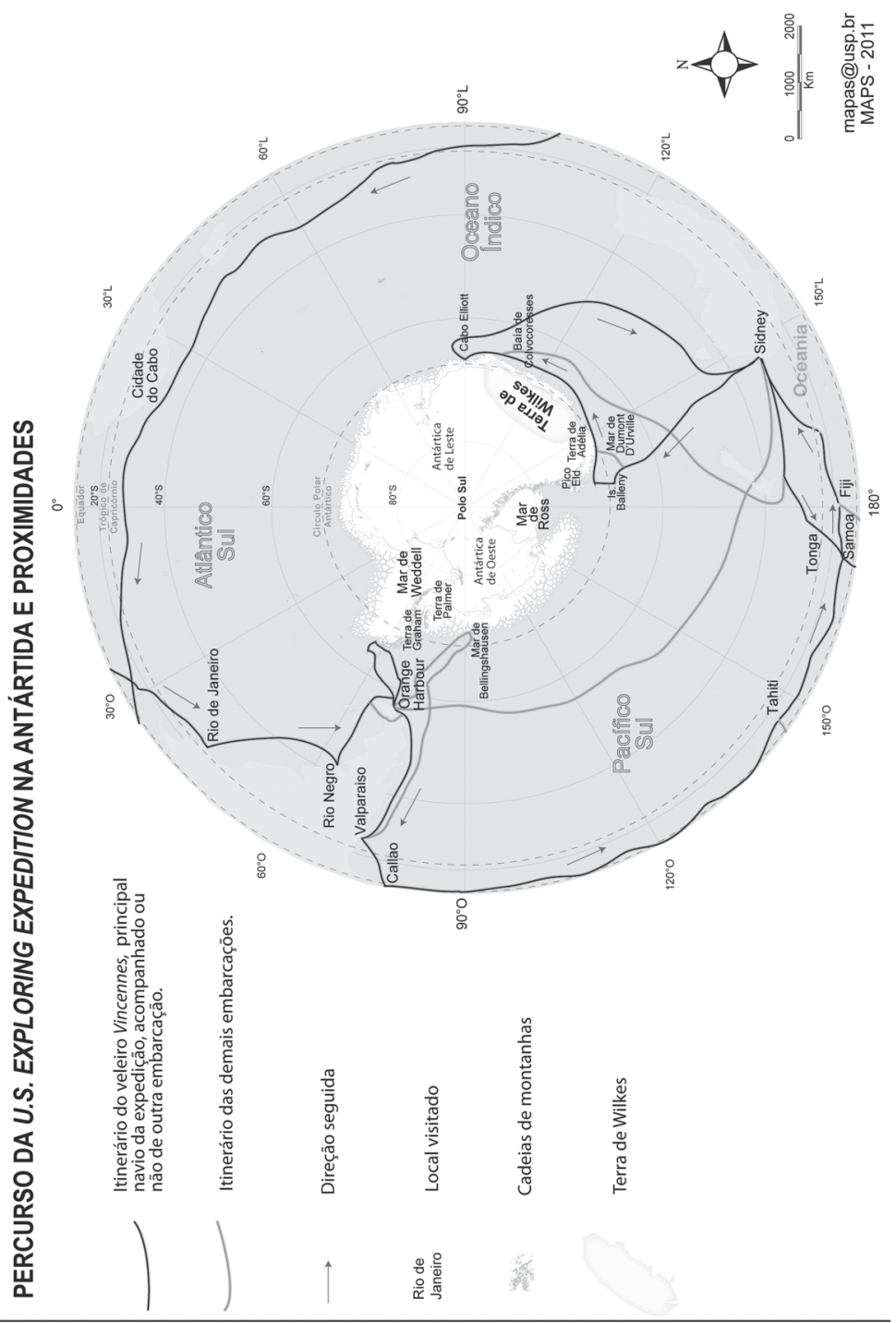

Anos 90, Porto Alegre, v. 22, n. 41, p. 55-82, jul. 2015 
Fonte: Elaborado por Mateus de Almeida Sampaio

Tal "descoberta" fez com que os mapas do globo existentes fossem redesenhados. A região já havia sido visitada por caçadores de focas; mas, apesar de hábeis navegadores, aqueles homens não dominavam o arcabouço científico-matemático que permitisse afirmar que a Antártida fosse um outro continente. A maioria nem sequer se interessava por essa constataçáo.

Como afirmei, Jeremiah Reynolds foi um dos lobistas a trabalhar junto ao Congresso para que a U. S. Exploring Expedition fosse aprovada. Wilkes não menciona Jeremiah Reynolds na narrativa de viagem, mas o faz na sua autobiografia, e náo esconde o incômodo com o espaço que Reynolds havia alcançado nos altos escalóes do governo.

O Sr. Jeremiah Reynolds, que era assistente de Simmes (sic), e acreditava firmemente na teoria da cavidade de Symmes próximo ao Polo Sul, transformou-se em aliado da empresa. Ele esteve sob as boas graças do secretario da Marinha, Saml Southard, que o indicou para reunir informaçóes dos baleeiros em portos do leste, com o objetivo de formar uma lista de ilhas, recifes e baixios, relatados no Pacífico Sul, mas ele estava inteiramente despreparado para a tarefa e, no entanto, foi muito considerado pelo governo. (WILKES, 1978, p. 322)

O excerto mostra-nos que Reynolds conquistara espaço, não só entre os altos escalóes do Congresso, mas também entre os da Marinha. Wilkes mostrou-se contrariado com a influência de um amador nos meios científicos. No entanto, o importante a ressaltar aqui é que as teorias científicas da época ajudaram a aprovar, no governo, a realização da U. S. Exploring Expedition, mesmo que depois elas perdessem a influência no trabalho posto a prova pela expedição.

Alguns navios da expedição dirigiram-se para o sul em operação arriscada em meio a icebergs, enquanto outros permaneceram ancorados em regióes seguras. Eles estiveram na Antártida por duas vezes: uma a partir da Terra do Fogo e outra a partir da Oceania. Enquanto algumas embarcaçóes aventuravam-se mais ao sul, outras permaneciam em segurança e em apoio aos expedicionários que se arriscavam mais e mais. Wilkes, em razão da sua constatação, 
deu nome a uma extensa regiáo no continente gelado, exatamente na porção onde avistaram terra no lugar, o que comprovou que a Antártida era, sim, um outro continente.

\section{Legenda: Veleiro Vincennes em Disappointment Bay - Antártida}

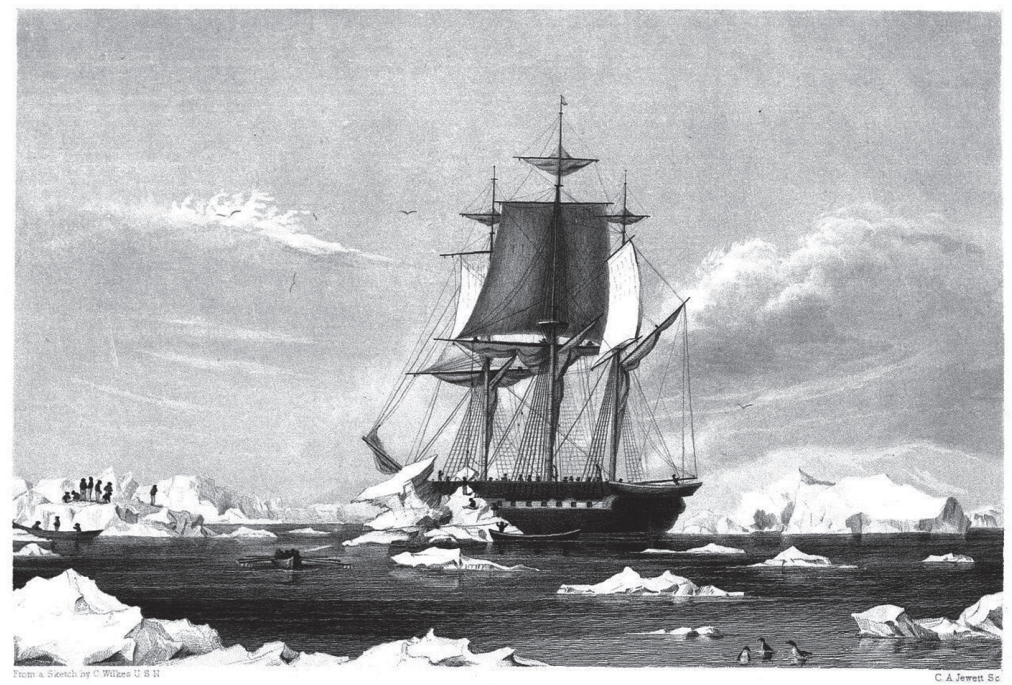

Fonte: (WILKES, Narrative, 1845, v. 2, p. 328).

Como já mencionado, o feito da U. S. Exploring Expedition foi alvo de contestação e houve disputas entre as potências pela primazia da descoberta. Na narrativa de viagem, Wilkes iniciou o assunto com cuidado, mas com decisão:

Os assuntos aos quais me remeterei nos próximos capítulos são exclusivamente náuticos. Portanto, devo tratá-los mais na forma de um diário de bordo (log-book), e seguir a ordem cotidiana de sua ocorrência no mais estrito que considere até 
agora necessário. Isso será feito com a intenção de ilustrar mais completamente a natureza das regióes remotas que atravessamos e com o objetivo de indicar a mais exata relação de incidências de parte de nossa viagem — incidências as quais eu posso senão esperar, que fizeram parte do nosso trabalho, particularmente interessantes a todos os nossos compatriotas que possuem um sentimento de orgulho nacional. (WILKES, Narrative, v. 2, 1844, p. 297).

O comandante afirma aqui que tratará do assunto como em um log-book; portanto, com base em dados e fatos registrados, sequencialmente, durante o cotidiano da expedição e já sustenta que a descoberta é motivo de orgulho nacional. Ele continua:

O crédito dessas descobertas tem sido reivindicado por parte de uma nação estrangeira, e até certo ponto, colocada em questão a verdadeira existência [se a Antártida era um outro continente ou não] por outra, ambas as expediçóes rivalizavam com suas Expediçóes no estrangeiro, uma no mesmo período [que a U. S. Exploring Expedition] e outra no ano seguinte. (WILKES, Narrative, v. 2, 1844, p. 297)

Como mencionado, um dos navios da U. S. Exploring Expedition encontrou-se com a embarcação do comandante francês, Dumont d'Urville, na Antártida, em uma inacreditável coincidência. A França é a primeira nação da qual Wilkes trata no excerto. Os franceses reivindicavam para si o feito. A segunda delas é a Inglaterra, do comandante James Clark Ross (1839-1843). Ross comandou os navios Erebus e Terror em expedição à Antártida um ano depois dos norte-americanos deixarem o continente gelado, mas antes dos norte-americanos retornarem finalmente às águas nacionais. ${ }^{3}$ Para Wilkes, França e Inglaterra subestimavam a façanha norte-americana.

Cada uma dessas nações, não me deterei a discutir, já que me parecem dispostas a nos roubar a honra e subestimar a própria importância de suas pesquisas, e restringir a terra encontrada na Antártida à pequena parte que eles respectivamente viram. 
Embora estivesse propenso a manter reserva para evitar contestar as proposiçóes deles, acredito que, devido à honra de nossa bandeira, devo declarar a prioridade da reivindicação da expedição norte-americana e da enorme extensão das nossas pesquisas e descobertas. (WILKES, Narrative, v. 2, 1844, p. 297)

Nesse excerto, é clara a concorrência dos norte-americanos com os europeus em empunhar a bandeira da descoberta científica. Segundo ordens do secretário da Marinha, os resultados da U. S. Exploring Expedition só poderiam vir a público com a edição do relatório de viagem, devidamente aprovado pelos altos escalóes da U. S. Navy e pelo Congresso do país. Wilkes, entretanto, sabendo da movimentação de navios ingleses e franceses na região da Antártida, com o pretexto de trocar informaçôes com o capitão Ross, enviou longa carta a ele, juntando carta náutica especialmente desenhada pelo próprio comandante da U. S. Exploring Expedition, na qual indicava que a Antártida era um outro continente. A carta de Wilkes continha uma série de dados sobre a região, além de informaçóes sobre temperatura, incidência dos ventos, posições do polo magnético etc. (WILKES, 1845 , p. 479-483). Assim mesmo, a querela continuou nos anos seguintes e repercutia ainda quando Wilkes escrevia a narrativa da viagem entre 1842 e 1843 .

A existência de terra no círculo antártico está agora confirmada pelos testemunhos de navegadores ingleses e franceses. D'Urville, o celebrado navegador francês, poucos dias após desembarcar em uma pequena ponta de rocha, no lugar (como suponho) que tenha aparecido para nós na Baía de Piner, que ele chamou de Terra de Clarie e onde testemunhou a existência de uma vasta extensão de terra, e também onde o Vincennes foi compelido por violenta tormenta. Nesse mesmo lugar, nossa inspeção não deixou dúvidas da sua existência [de terra]. Ross, por sua vez, penetrou a latitude de $79^{\circ}$ no ano seguinte, navegou pela costa, ao longo de uma alta região conectada com o nosso continente da Antártida, e estabeleceu, além de qualquer sofisma, a correção de nossa asserção: o que nós descobrimos não são os limites de ilhas 
separadas, mas um vasto continente antártico. (WILKES, Narrative, v. 2, 1844, p. 297-298).

Aqui, o comandante afirma que ingleses e franceses atestavam que a Antártida era um continente, mas não creditavam o feito aos norte-americanos. Assevera que D’Urville constatou a descoberta, mas afirma que norte-americanos estavam no local antes do encontro com o francês. Lugar, inclusive, que o Vincennes havia sido arrastado por uma tormenta. Ele também rebate o fato do inglês, Ross, afirmar que, conforme a regiáo que os norte-americanos se encontravam no continente gelado, Wilkes só podia ter constatado a existência de ilhas e não propriamente um outro continente, como ele, Ross, de fato e de direito, atestava.

Wilkes afirmou também que o inglês chegou tão longe por causa de descobertas da U. S. Exploring Expedition. Disputas científicas por parte de militares-cartógrafos - portanto também disputas de poder —, estavam em debate nos relatos e relatórios de viagem da época.

Quão longe o Capitão Ross foi guiado em suas pesquisas por nossas descobertas anteriores, as quais aparecerão melhor na referente carta náutica, juntamente à completa descrição dos procedimentos da esquadra que eu enviei a ele e que foi anexada no apêndice XXIV e no Atlas [da narrativa de viagem da U. S. Exploring Expedition], embora eu não tenha recebido qualquer agradecimento de sua parte [...]. A narrativa que se segue, creio, não deixará dúvidas em quaisquer dos espíritos sobre a justeza da alegação de que nós descobrimos um vasto continente; no entanto, eu perguntaria de antemão: quem esteve lá [na Antártida] antes de 1840, seja desse país [Estados Unidos] ou da Europa que tenha tido ao menos a ideia de que um grande corpo de terra existisse ao sul de New Holland [Tasmânia]? E quem, quando esteve lá, não duvidou de que fosse um vasto continente ou sustentou ser apenas um conjunto de ilhas? Quando se examinam todos os mapas e as cartas publicadas até a época, existe algum indício de que terra [continente] foi encontrada? Não há, e, pela melhor das razões, ninguém sabia ou suspeitou que ela existisse. Nós 
antecipamos não apenas tal descoberta. As indicaçóes eram de que tal achado fosse recebido com dúvidas e hesitaçóes. Eu mesmo não me aventurei a registrar no meu diário pessoal essa certeza, até três dias após o melhor discernimento e até que o conhecimento fosse de fato assegurado, para finalmente remover todas as possibilidades de dúvida e provar conclusivamente que não havia engano nesse caso, visto que foram feitas inspeçóes sobre a mesma porção de terra a partir dos veleiros em três diferentes posiçôes. (WILKES, Narrative, v. 2, 1844, p. 298)

Ainda que Wilkes afirmasse que ia se ater apenas aos fatos - e realmente, nas páginas seguintes da narrativa, apresentou o passo a passo da descoberta de terra entre o gelo - , a parte da narrativa que trata dessa questáo é, sem dúvida, a defesa da primazia da descoberta pela U. S. Exploring Expedition sob bandeira dos Estados Unidos.

\section{A formação de quadros no campo das Ciências Naturais}

Com base no exposto até aqui, é possível discutir o que venho tratando neste artigo: os Estados Unidos não pretendiam apenas um saber local - em prol da independência, em alguns campos, com relação à Europa -, mas também à sua inserção nos domínios das redes de conhecimento transnacionais.

$\mathrm{Na}$ primeira metade do século XIX, os norte-americanos distinguiam os contornos de determinados campos do saber, inspirando-se nas matrizes europeias e, consequentemente, investindo na profissionalização de quadros tanto na área militar (Exército e Marinha) quanto na acadêmica. Sabe-se que as relaçóes entre oficiais e cientistas eram estreitas e que, em muitos casos, ambos serviam o país em operações oficiais mantendo o convívio cotidiano. Em geral, militares e civis cientistas faziam parte do grupo dos gentlemen da jovem República (HUNTER, 2010). Por exemplo, vários deles eram membros da American Philosophical Society of Philadelphia, associação científica que acompanhava com interesse a expedição e que muniu o capitão, os oficiais e cientistas com informaçôes e 
indicaçóes para a viagem. ${ }^{4}$ Participaram da exploração os seguintes cientistas, já citados em excerto incluído anteriormente:

- James Dwight Dana (mineralogista);

- Titian R. Peale (naturalista);

- Charles Pickering (naturalista);

- Joseph Pitty Couthouy (conquilologista);

- William Rich (botânico);

- William Dunlop Brackenridge (botânico assistente, especialista em horticultura);

- Horatio Hale (filólogo);

- Alfred Thomas Agate (artista);

- Joseph Drayton (artista) ${ }^{5}$.

Entre os altos quadros que embarcaram nos veleiros da U. S. Exploring Expedition, esses eram os civis da operação. Quando os nomes para congregar o corpo de cientistas estavam para ser indicados, uma das recomendaçôes era a de que todos os escolhidos fossem nascidos em território nacional, fato que reforça o que examino aqui: a intençáo dos norte-americanos em qualificar quadros e instituir um saber próprio, "nacional", tornando-se independentes dos europeus em determinados campos do conhecimento. Porém, a carência de especialistas fez com que se indicasse o escocês William Brackenridge, horticulturista e único membro do corpo civil de cientistas nascido fora do território norte-americano. Cientistas, tanto quanto oficiais e marinheiros, eram pagos pelo governo dos Estados Unidos. Wilkes revela na sua autobiografia:

A tarefa mais difícil que tive que cumprir foi a seleção do corpo científico. Eram vinte sete, incluindo artistas, taxidermistas e assistentes, os quais foram necessariamente reduzidos em número, para que pudessem ser acomodados, para sete. Eles recebiam honorários [do governo] e muitos deles tinham fortes interesses e muitos amigos que recomendaram suas qualificaçóes. Ao examinar o corpo de cientistas, logo percebi aqueles mais capazes em vários departamentos, os quais foram selecionados, notificados. Solicitou-se que se mantivessem em atenção para o embarque o qual seria brevemente informado. Selecionei os nomes e empenhei-me em 
fazê-lo imparcialmente, tendo como referência as suas habilidades. Eles estavam sendo remunerados, e, por meu desejo, foram mantidos em inteira ignorância [sobre os propósitos da expedição], exceto alguns. Enquanto fossem pagos, como falei a Mr. Poinsett, eles manteriam segredo [...]. Uma semana antes de zarpar, eles receberam ordens para embarcar nos navios Vincennes, Peacock e Relief (WILKES, 1978, p. 345)

$\mathrm{O}$ excerto revela vários aspectos dessas viagens estratégicas. O mais notável deles é o fato de oficiais e cientistas nem sempre serem informados dos reais propósitos das expediçóes. Revela que a operação foi totalmente patrocinada pelo governo, inclusive o trabalho dos cientistas. Certamente, aqueles homens contavam que o trabalho realizado durante a expedição os qualificaria para postos mais ambiciosos no futuro. Mais: o fato de alguns cientistas serem pagos pelo governo garantia o seu silêncio a respeito do trajeto da expedição. Como veremos, assim foi.

A respeito da profissionalização em determinadas áreas do saber, um bom exemplo é o da Botânica, praticamente inexistente nas universidades dos Estados Unidos antes da circum-navegação. Foram convidados a integrar o corpo de cientistas Asa Gray e Charles Pickering, os dois médicos que, nas horas vagas, dedicavam-se ao estudo das plantas. Como a expedição atrasava, por causa dos preparativos, Asa Gray declinou do convite, pois aceitara o que foi considerado um dos primeiros postos de professor de Botânica na nova Universidade de Michigan. Em 1842, ele foi convidado para lecionar na Universidade de Harvard, onde fez carreira, tornando-se conhecido e respeitado nos meios científicos nacional e internacional. Para o seu lugar, fora convidado William Brackenridge que, com William Rich, firmou-se como botânico, após o retorno da U. S. Exploring Expedition.

O fato de Asa Gray não ter participado da expedição não significou a sua exclusão do produto final da operação: o relatório da viagem. Era possível que, a partir dos espécimes coletados, os cientistas em terra, e não participantes da expedição, organizassem a classificação das coleções. 
Gray foi especialmente convidado para escrever três volumes científicos da expedição sobre Botânica. Ele organizou os três, mas apenas dois chegaram a ser publicados. Asa Gray não foi o único caso de cientista a contribuir com o relatório de viagem, em particular, com os volumes científicos, sem ter participado dos quatro anos da viagem exploratória. Augustus Addison Gould, também ex-médico, igualmente interessado na Botânica, acabou por se especializar em conquiliologia e foi convidado a escrever o volume sobre moluscos e conchas, publicado em 1852.

Além desses, o ornitologista e taxonomista John Cassin encarregou-se de um dos dois volumes sobre mamíferos e ornitologia, de título Mammalogy \& Ornithology, Spencer Baird organizou os volumes sobre répteis e Louis Agassiz foi convidado a organizar os volumes XXI e XXII, sobre peixes, os quais não chegaram a ser publicados.

Já Charles Pickering, aceitara de bom grado o posto de naturalista da expediçáa. Era homem preocupado com a distribuição das "raças de homens sobre o globo", relacionando-os com as suas respectivas regiôes climáticas (determinados grupos mais "evoluídos e civilizados" habitavam geografias de climas temperados, e os de clima tropical eram, em geral, pouco dados ao engenho do trabalho, conformando outro "estágio de evolução"). A viagem ofereceu a Pickering a oportunidade de "constatar" determinadas teorias sobre a distribuição de populaçóes pelo planeta. Em 1848, após viagem que fez a Índia e a África, lançou o livro pelo qual seria reconhecido na área de Etnologia, campo que também se formava na época, de título Races of man: and their geographical distribution, originalmente um dos volumes científicos da expedição (o de número IX), publicado em $1848 .{ }^{6}$

Diferentemente dos cientistas citados, James Dwight Dana já atuava como professor-assistente no laboratório de Química, na Universidade de Yale. Ele fora indicado para participar da expedição como mineralogista, embora tenha preparado também o volume sobre zoófitos. Os volumes apresentados por Dana, após alguns anos de estudos, tornaram-se reconhecidos rapidamente, e ele se tornou um dos mais preeminentes especialistas em mineralogia nos Estados Unidos. O seu trabalho mais conhecido é o Manual of mineralogy, publicado pela primeira vez em 1848, o qual ganhou revisóes, acréscimos e várias ediçôes, permanecendo como referência até os dias atuais. 
Segundo William Stanton, Asa Gray, James Dwight Dana e Charles Pickering foram precursores das posteriores geraçôes de cientistas dos Estados Unidos (STANTON, 1975, p. 44), no que dizia respeito aos vínculos com as universidades e com outras instituiçóes científicas, e no que concerne a publicaçóes de livros sobre os seus campos de interesse. Asa Gray, por exemplo, manteve fecunda correspondência com Charles Darwin e foi um dos defensores da teoria da evolução das espécies nos Estados Unidos.

Alguns dos cientistas deveram a sua carreira à expedição exploratória, graças às observações e análises, realizadas durante muitos anos, do que foi coletado. Além do já citado Manual of mineralogy, o relatório de Dana sobre os vulcóes do Hawaii e sobre as ilhas da Polinésia, entre outros, foi considerado referência em Geologia.

A formação de quadros qualificados em distintos ramos das ciências, nas áreas acadêmicas e militares, é notada por George Daniels, segundo o qual, entre 1812 e 1842, a ciência dos Estados Unidos teve o seu start - a sua arrancada. Daniels afirma que, na época, os cientistas norte-americanos evoluíram de um "[...] desordenado grupo de amadores sem direcionamentos precisos para se constituírem, já em 1850, em um corpo recém-organizado de cientistas profissionais, ocupando cargos em universidades e em instituiçóes públicas." (DANIELS, 1984, p. 7)

Quando da expedição, os cientistas, além de descer em terra para coletar espécimes, realizavam incansável trabalho a bordo, segundo William Reynolds, aspirante a oficial que acreditava que os anos servindo na exploração ajudaria a alavancar a sua carreira:

Os cientistas cortam em pedaços, dissecam, examinam e usam o seu magnífico poder de ver, fazem desenhos e pinturas, pesquisam em seus livros, escrevem e registram descriçóes, inventam termos impronunciáveis e nos falam sobre todos os mistérios da organização [classificação do material coletado]. Eles têm lagartos vivos e mortos, peixes flutuando em álcool, queixadas de tubaróes, tartarugas empalhadas, vertebrados e animaculae saltando em água e sal, velhas conchas e muitas outras peças igualmente interessantes penduradas sobre suas camas e espalhadas pelos quartos - esses encantadores objetos 
indubitavelmente agradam aos olhos dos cientistas e os levam à contemplaçáo. Levar alguns deles para o meu quarto? - não, não! Eu os visitarei quando tiver curiosidade. (REYNOLDS, 2004, p. 13)

O oficial admirava o trabalho dos cientistas e despendia muito do seu tempo livre junto a eles, mas, bem-humorado, afirma que preferia dormir em lugar diferente daquele que descreveu.

\section{Ambiguidades com relaçáo à Europa}

As viagens de circum-navegação, como outras expediçôes científicas da época, eram operaçôes coloniais que pretendiam investigar um mundo considerado "classificável", mensurável e explorável; em outras palavras, passível totalmente de verificação e apreensão (PENHOS, 2007). Convictos dos usos da racionalidade e dos preceitos modernos da ciência que alicerçavam-se no empirismo de Bacon (1561-1626) - filosofia que dominava particularmente os meios científicos ingleses e adotada com entusiasmo pelos norte-americanos - e e na taxonomia proposta por Carl Linnaeus (17071778), renomado por instituir a nomenclatura que tornava possível a classificação do mundo natural (PRATT, 1999).

A distinção da U. S. Exploring Expedition pode ser medida não com relação a seus métodos e características, uma vez que essa viagem exploratória era devedora das expediçôes realizadas por europeus, como já indicamos. Aliás, o melhor seria dizer que as viagens de circum-navegação - e outras de cunho científico - eram devedoras umas das outras. A particularidade da exploraçáo estava no fato de os norte-americanos se utilizarem dos padrôes científicos instituídos pelos europeus para buscarem independência, em termos da construção de um corpo de saberes, da própria Europa.

Como já indicado, a própria realização da expedição é uma evidência da busca dos norte-americanos em estabelecer um saber local, com cientistas e oficiais capazes de manter interlocução com os seus pares europeus, na primeira metade do século XIX. Provavelmente, foi essa busca por independência nos campos do saber que motivou 
o pensador, Ralph Waldo Emerson, a pronunciar palestra de título: American scholar, numa sociedade acadêmica. Segundo ele, os norte-americanos tinham "[...] escutado por muito tempo as envolventes musas da Europa [...]" e afirmou: "[...] nós andaremos com os nossos pés, trabalharemos com as nossas mãos, e expressaremos a nossa própria opiniāo" (apud STANTON, 1982, p. 84).

Se, por um lado, os norte-americanos procuravam se distanciar da Europa, instituindo um saber nacional, eles buscavam, por outro, reconhecimento dos europeus e inserção nas redes de conhecimento, como já mencionado. A admiração pelos cientistas ingleses é digna de nota. Charles Wilkes, após aprovação da expedição científica pelo Congresso, viajou para a Inglaterra com o objetivo de comprar instrumentos de precisão e lá permaneceu por cinco meses. $\mathrm{Na}$ Inglaterra, teve contato com cientistas e oficiais da Royal Navy, inclusive com Robert FitzRoy, o comandante do Beagle, quando da famosa circum-navegação do navio. Foi convidado a participar de um jantar na Royal Astronomical Society, onde conheceu Peter Barlow, reconhecido especialista em magnetismo da época, e Francis Baily, vice-presidente da sociedade.

Quando na Inglaterra, Wilkes escreveu uma carta à sua mulher, revelando enfático entusiasmo em frequentar as rodas da elite científica mundial, particularmente as daquele país que comportava a maior Marinha da época e com oficiais treinados em vários ramos da ciência. "Sinto-me mais à vontade entre esses gigantes [...]", escreveu ele a Jane Wilkes (PHILBRICK, 2008, p. 58).

O comandante não escondeu a excitação ao deixar o extremo sul da América do Sul para alcançar a Antártida, na senda do inglês James Cook.

Logo que chegamos ao Porto de Orange, estivemos em ativas preparaçôes para uma curta viagem à Antártida. Embora a estação [verão] já estivesse próxima do fim, ao menos antecipei alguma experiência entre o gelo [icebergs]; e supus que o fim da estação o teria desprendido das praias da Terra de Palmer, e permitiria uma aproximação tanto quanto possível do seu principal corpo ou barreira, nas vizinhanças do Ne Plus Ultra de Cook. [...] Ordenei ao capitão Hudson do Peacock, e o 
Flying Fish, sob ordens do tenente Walker, como apoio, que deveriam se dirigir a oeste tão longe quanto o Ne Plus Ultra de Cook. (WILKES, Narrative, 1845, v. 1 p. 124).

Wilkes seguiu no veleiro Porpoise, procurando alcançar as regióes ainda mais ao sul, ultrapassando Cook. As intençóes do comandante transbordam das páginas da narrativa. Ele admirava profundamente o inglês e simultaneamente procurava superar o militar, empenhando-se em glórias próprias e fincando a bandeira do seu país entre as grandes expedições ocidentais.

A relação com a Europa, em particular com a Inglaterra, na narrativa de cinco volumes, oscila entre a admiração e a concorrência. No texto, sobrepóem-se a voz de um jovem país "adquirindo competência, autonomia e autoridade", capacitado a julgar, descrever e classificar o mundo - e a voz do país que havia sido colonizado e que imputava à Europa o modelo a ser seguido ou comparado, buscando de uma maneira ou outra ganhar o seu reconhecimento.

Quero dizer que os norte-americanos, com a U. S. Exploring Expedition buscavam se posicionar como um local de saber, contudo um local que carregava uma relação ambígua com a Europa. De acordo com Ricardo Salvatore, que se apoiou em autores como Edward Said e Dispesh Chakrabarty, afirma que o ocidente [...] foi sustentado por uma metanarrativa que afirmou a superioridade científica e tecnológica, impôs os modos de pensar a História, tomou controle do estudo das línguas e raças do mundo e ajudou a manter polaridades que apontavam aquela superioridade, tais como: ciência/ crença, razão/superstição etc (SALVATORE, 2007, p. 13). É em referência ao discurso de autoridade europeu que se desenvolve, entre tensóes e afirmaçóes, o discurso de autoridade do relatório de viagem da U. S. Exploring Expedition.

Se, por um lado, os Estados Unidos buscavam se tornar independentes da Europa em termos de acúmulo de conhecimento científico, o país, por outro, colocava-se como orgulhoso partícipe da raça anglo-saxônica, a única capaz de levar a bom termo a "tarefa da civilização”. A relação com a Europa e os europeus mostrou-se ambígua: em determinados momentos, os norte-americanos colocavam-se ao lado dos ingleses e, em outros, distanciavam-se 
e concorriam com eles. Embora sejam, nos dias de hoje, a maior potência do planeta, é inegável que os Estados Unidos — entáo na "periferia" da Europa - debate(ra)m-se, como outros países das Américas, com as marcas da colonização.

\title{
The United States between the national and transnational: the knowledge produced by the scientific circumnavigation of the US Exploring Expedition (1838-1842)
}

\begin{abstract}
This article analyzes some of the aspects of modern knowledge that were expressed in the travel writing of the first scientific circumnavigation by the US Exploring Expedition between 1838 and 1842. The knowledge assimilated by that expedition included aspects of national assertion as well as transnational issues of the era. The article analyzes the North American approach with respect to the insertion of North American influence into the network of knowledge that was led by European nations at that time; this represented a discussion with their peers of the old continent, but also direct competition with them.

Keywords: United States. Circumnavigation. Science. National. Transnational. (Endnotes)
\end{abstract}

\section{Notas}

${ }^{1}$ Edgard Allan Poe (1997) tratou da teoria de Symmes e Reynolds no romance $O$ relato de Arthur Gordon Pym.

${ }^{2} \mathrm{O}$ círculo polar Ártico não é considerado um continente, pois não há terra abaixo da superfície de gelo como na Antártida.

${ }^{3}$ Ross era conhecido oficial da Marinha inglesa e foi um dos que tentou encontrar a famosa passagem à noroeste que supunham existir no Ártico, entre 1819 e 1827. O mar de Ross, na Antártida, foi batizado assim em sua homenagem. 
${ }^{4}$ A American Philosphical Society existe ainda hoje. Com origem na colônia da Pensilvânia, foi fundada sob os princípios iluministas do século XVIII. Após a Independência do país, em 1776, transformou-se em sociedade que congregava os interessados em ciência de todo o país.

${ }^{5} \mathrm{O}$ naturalista preocupava-se tanto com fauna e flora quanto com os grupos humanos. Titian Peale voltou-se para fauna, enquanto Charles Pickering preocupava-se com a distribuição dos grupos humanos pelo globo. Embarcaram também na expedição o intérprete F. L. Davenport, que abandonou a expedição ao chegar ao Rio de Janeiro, e John W. W. Dyes (taxidermista). Wilkes incluiu entre o corpo de cientistas John W. Brown, matemático e especialista em instrumentos de alta precisão, dedicado, portanto, a um trabalho mais técnico.

${ }^{6}$ A American Ethnological Society, a mais antiga associação que inicialmente reunia interessados em Etnologia e línguas dos nativos dentro e fora do país, foi fundada por Albert Gallatin e John Russell Bartlett, em 1842. Gallatin foi o responsável por orientar cientistas e oficiais da U. S. Exploring Expedition quanto aos procedimentos a serem adotados em relação às línguas indígenas. Logo após a fundaçáo, a associação científica incorporou a questão do negro e da escravidão entre os seus temas de interesse. (FREDRICKSON, 1971; BIEDER, 1989)

\section{REFERÊNCIAS}

BAEZA, Rafael Sagredo; LEIVA, José Ignácio Gonzáles. La expedición Malaspina en la frontera austral del imperio español. Santiago de Chile: Editorial Universitaria, 2004.

BIEDER, Robert E. Science encounters the Indian 1820-1880. The early years of American Ethnology. Norman: University of Oklahoma Press, 1989.

DANIELS, George. America science in the age of Jackson. Tuscaloosa-Alabama: The University of Alabama Press, 1984.

DESMOND, Adrian; MOORE, James. Darwin. A vida de um evolucionista atormentado. São Paulo: Geração Editorial, 2000. 
DICK, Steven. "Centralizing Navigational Technology in America: The U. S. Naval Depot of Charts and Instruments, 1830-1842". Technology and Culture. Baltimore, v. 33, Jul. 1992.

EHRENBERG, Ralph; WOLTER, John; BURROUGHS, Charles. Surveying and charting the Pacific basin. In: VIOLA, Herman; MARGOLIS Carolyn (Orgs.). Magnificent voyagers. The U. S. Exploring Expedition, 1838-1842. Washington: Smithsonian Institution Press, 1985.

FREDRIKSON, George M. Science, polygenesis, and pro-slavery argument. The Black image in the White mind. The debate on Afro-american character and destiny, 1817-1914. New York: Harper \& Row, 1971

HUNTER, Mark C. A society of gentlemen. Midshipment at the U. S. Naval Academy 1845-1861. Annapolis: Naval Institute press, 2010.

JUNQUEIRA, Mary Anne. Charles Wilkes, a U. S. Exploring Expedition e a busca dos Estados Unidos da America por um lugar no mundo. In: Tempo. Rio de Janeiro: Revista do Departamento de História da UFF, Rio de Janeiro, v. 25, 2008.

. Os objetivos da circunavegação da U.S. Exploring Expedition (18381842): longitude, mapeamento náutico e instituição das coordenadas geográficas modernas. Hist. cienc. saúde-Manguinhos. Rio de Janeiro: v. 19, 2012.

NEIL, Safier. Measuring the New World. Enlightenment science and South America. Chicago: The Chicago of University Press, 2008.

PENHOS, Marta. De la exactitude Del conoscimento. Malaspina em la Patagônia (1789). In: SALVATORE, Ricardo. Los lugares del saber. Contextos locales y redes transnacionales en la formación del conocimiento moderno. Rosario: Beatriz Viterbo, 2007.

PHILBRICK, Nathaniel. Mar de glória. Viagem americana de descobrimento. São Paulo: Companhia das Letras, 2003.

POE, Edgard Allan. O relato de Arthur Gordon Pym. São Paulo: L\&PM/ Pocket, 1997.

PRATT, Mary Louise. Ciência, consciência planetária, interiores. Os olhos do império. Relatos de viagem e transculturação. Bauru: Edusc, 1999.

REYNOLDS, William. The private journal of William Reynolds. United States Exploring Expedition, 1838-1842. New York: Penguin Books, 2004.

SAFIER, Neil. Measuring the New World. Enlightenment science and South America. Chicago: University of Chicago Press, 2008. 
SALVATORE, Ricardo. Los lugares del saber. Contextos locais y redes transnacionales em la formación del conocimento moderno. Rosario: Beatriz Viterbo Editora, 2007.

STANTON, William Ragan. The great United States Exploring Expedition of 1838-1842. Berkeley: University of California Press, 1975.

The Leopard's spots. Scientific attitudes toward race in America 1815-59.

Chicago: The University of Chicago Press, 1982.

VIOLA, Herman J. The story of the U. S. Exploring Expedition. In: VIOLA, Herman J.; MARGOLIS, Carolyn (Orgs.). Magnificent voyagers. The U. S. Exploring Expedition, 1838-1842. Washington: Smithsonian Institution Press, 1985.

WILFORD, John Noble. The mapmakers. New York: Vintage Books, 2000.

WILKES, Charles. Narrative of The United States Exploring Expedition - 18381842, Vol. I, 1844.

. Autobiography of Rear Admiral Charles Wilkes. U.S. Navy 1798-1877, Washington: Naval History Division, 1978.

WILSON, Derek. A brief history of the circumnavigators. The pioneer voyagers who set off around the globe. London: Robinson, 2003.

Recebido em: 18/11/2014 Aprovado em: 26/03/2015 